\title{
Abnormal Anatomical Location of Root of Second Premolar in Mental Foramen: A Very Rare Case
}

\author{
${ }^{1}$ Pulkit Khandelwal, ${ }^{2}$ Shirish Dubey, ${ }^{3}$ Neha Hajira
}

\begin{abstract}
Mental foramen is a key factor in many of the surgical procedures. While carrying out surgical procedures in premolar region, the knowledge of anatomy of mental nerve and its foramen is of utmost importance to avoid intraoperative neurovascular damage and to avoid postoperative neurosensory disturbances. The variations of mental foramen with respect to position, size, and number are very well documented. However, in very rare cases, length of the premolar roots may be abnormally long or abnormally positioned, which can impinge on the mental nerve or may enter mandibular canal or mental foramen. We present one such rare case where second premolar root was impinging on the mental nerve and producing symptoms. Extraction of second premolar was done and patient became asymptomatic postoperatively.
\end{abstract}

Keywords: Mental foramen, Mental nerve, Pain, Premolar.

How to cite this article: Khandelwal P, Dubey S, Hajira N. Abnormal Anatomical Location of Root of Second Premolar in Mental Foramen: A Very Rare Case. Int J Experiment Dent Sci 2016;5(1):76-77.

Source of support: Nil

Conflict of interest: None

\section{INTRODUCTION}

The mental foramen (MF) is an opening on the anterolateral surface of the mandible. The inferior alveolar nerve and artery, after traveling through the mandibular canal, exit at the MF as the mental nerves and vessels that innervate the lower teeth, lip, gingival, and soft tissues of chin area. The foramen opens directed posteriorly, outward, and upward. There can be neurosensory disturbances encountered if this important landmark is ignored while doing any invasive treatment in this region. Thus, it is important to have knowledge of the probable location

\footnotetext{
${ }^{1,3}$ Senior Lecturer, ${ }^{2}$ Consultant

${ }^{1}$ Department of Oral and Maxillofacial Surgery, Pacific Dental College and Hospital, Udaipur, Rajasthan, India

${ }^{2}$ Department of Oral and Maxillofacial Surgery, IRIS Hospital Kolkata, West Bengal, India

${ }^{3}$ Department of Prosthodontics, Darshan Dental College Udaipur, Rajasthan, India
}

Corresponding Author: Pulkit Khandelwal, Senior Lecturer Department of Oral and Maxillofacial Surgery, Udaipur Rajasthan, India, Phone: 09049831636, e-mail: khandelwal. pulkit22@gmail.com of the MF. ${ }^{1}$ The most common position of MF is below the apex of the second premolar $(68.8 \%)$, second most common position is between first and second premolars (17.8\%) followed by third most common position between the second premolar and first molar. Very rarely, MF is present below the apex of first premolar. ${ }^{2}$ Here, we report an extremely rare case where premolar root was found to be so long that it was entering MF and impinging on the mental neurovascular bundle.

\section{CASE REPORT}

A 40-year-old male was referred to our clinic by a private dental practitioner for removal of second premolar. The practitioner attempted extraction of second premolar, which unfortunately damaged the adjacent first premolar and first molar teeth leading to fracture of their crowns. Patient was suffering from severe pain in the lower left back tooth region since 2-3 months, and hence consulted the practitioner. Cone beam computed tomogram was done, which revealed an abnormally long and abnormally positioned root of second premolar in MF (Fig. 1). The root was longer than that of canine. The tip of the root was breaching the continuity of MF and was lying very close to the lower border of mandible. Considering the complexity of the condition, extraction of second premolar and other indicated teeth was planned under general anesthesia. Patient was explained about the condition and informed consent was taken. Second premolar was extracted by splitting through the lingual cortical bone and preventing any buccal movement of the tooth. Root stumps of first premolar and first molar were also extracted. No brisk vascular hemorrhage was encountered during the procedure. Postoperative recovery was uneventful and there was no neurosensory disturbance.

\section{DISCUSSION}

The average length of root of second premolar is approx $22.3 \mathrm{~mm}, 3.3 \mathrm{~mm}$ smaller than that of the mandibular canine. ${ }^{3}$ The apices of premolars are found to be very close to the MF. Wang et $\mathrm{al}^{4}$ reported that the average distance between the bottom of the lower second premolar socket and the superior border of the MF is approx. $2.5 \mathrm{~mm}$.

Iatrogenic injuries to the third division of the trigeminal nerve remain a common and complex clinical problem. 


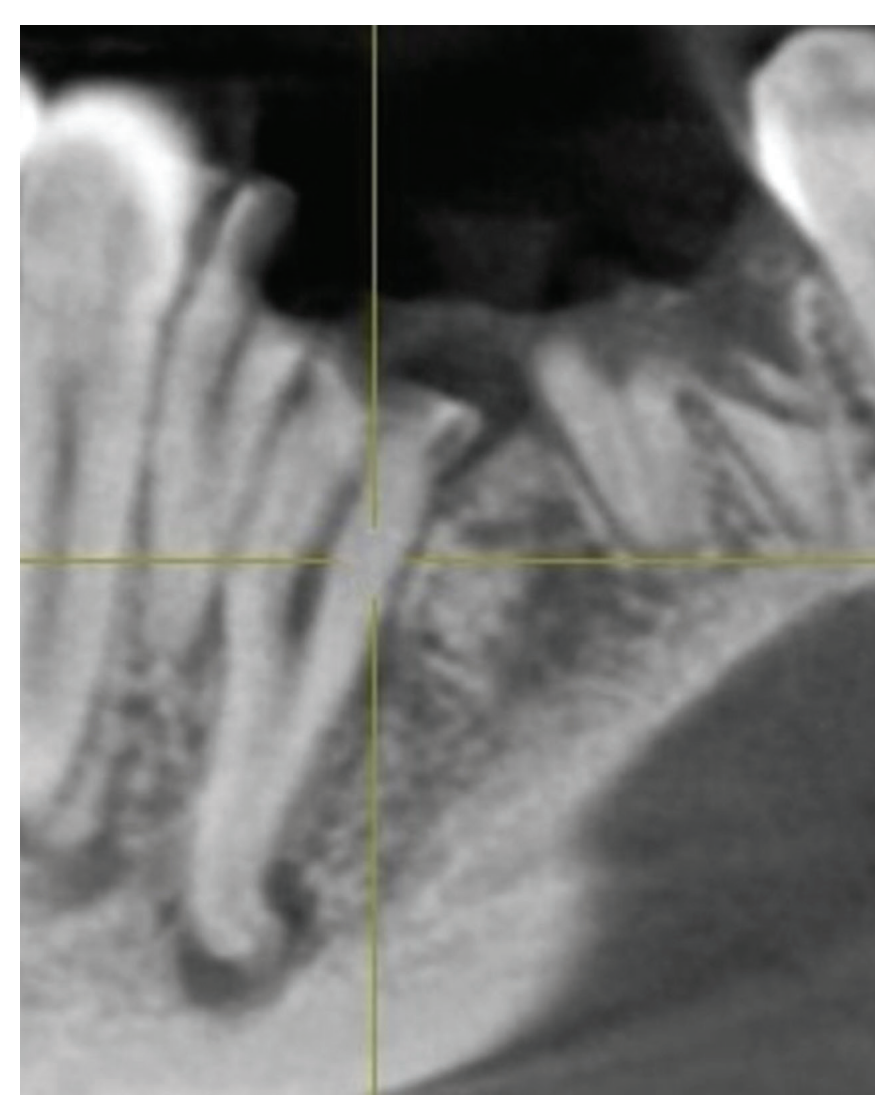

Fig. 1: A sectional view of cone beam computed tomogram revealing the abnormally long root of second premolar entering the mental foramen

Whenever extraction of mandibular posterior teeth is carried out, damage to the inferior alveolar nerve or any of its branches is possible, if canal and tooth root are in close approximation. Patient may suffer from abnormal sensations like burning, prickling, tingling, numbness, or itching. Altered sensation and pain in the involved areas may interfere with speaking, eating, drinking, shaving, toothbrushing, and other events of social interaction which will have a disturbing impact on the patient. Paresthesia can be short term, long term, or even permanent. The duration of the paresthesia depends upon the extent of the nerve damage or persistence of the etiology. ${ }^{5}$ The mental neurovascular bundle can be damaged during many surgical procedures, including administration of local anesthetic, implant bed preparation and placement, fracture reduction and fixation, mandibular orthognathic surgery, endodontics, and other surgical interventions. ${ }^{6}$
Surgical removal of mandibular premolar roots or impacted mandibular premolars or periapical surgery in the region of mental nerve and MF must be performed with great care. If mental nerve is injured, the patient may experience paresthesia or anesthesia of the lip or chin region. ${ }^{6}$

In our case, it was highly unfortunate that there was loss of first premolar and first molar due to inadequate preoperative evaluation and improper technique or inexperience of the previous clinician. The reason behind such unfortunate accident might be abnormally long and positioned root of second premolar, which would have made the attempt to extract second premolar a tedious and traumatic task. Fortunately, there was no neurovascular damage during the previous attempt. The surgery was done under general anesthesia because patient was not willing for the further procedure under local anesthesia. General anesthesia provided us with better treatment planning, in case of any brisk vascular hemorrhage. Tooth was extracted through lingual bone splitting.

\section{CONCLUSION}

It is imperative that dental practitioners should be aware of factors associated with difficult extraction and risk factors relating to neurovascular injuries. By understanding these risk factors and modifying any surgical intervention, more of these injuries can be prevented. Furthermore, if the injury occurs there are emerging strategies that may facilitate recovery.

\section{REFERENCES}

1. Aher V, Pillai P, Ali FM, Mustafa M, Ahire M, Mudhol A, Kadri M. Anatomical position of mental foramen: a review. Global J Med Public Health 2012 Jan-Feb;1(1):61-64.

2. Singh R, Srivastav AK. Evaluation of position, shape, size and incidence of mental foramen and accessory mental foramen in Indian adult human skulls. Anatomy 2011;5:23-29.

3. Carrotte P. Endodontics: Part 4. Morphology of the root canal system. Br Dent J 2004 Oct 9;197(7):379-383.

4. Wang TM, Shin C, Liu JC, Kuo KJ. A clinical and anatomical study of the location of the mental foramen in adult Chinese mandibles. Acta Anat (Basel) 1986;126(1):29-33.

5. Kiyak HA, Beach BH, Worthington $\mathrm{P}$, Taylor T, Bolender C, Evans J. Psychological impact of osseointegrated dental implants. Int J Oral Maxillofac Implants 1990 Spring;5(1): 61-69.

6. Hupp JR, Tucker MR, Ellis E III. Contemporary oral and maxillofacial surgery. 6th ed. St Louis, MO: Elsevier 2014. 